
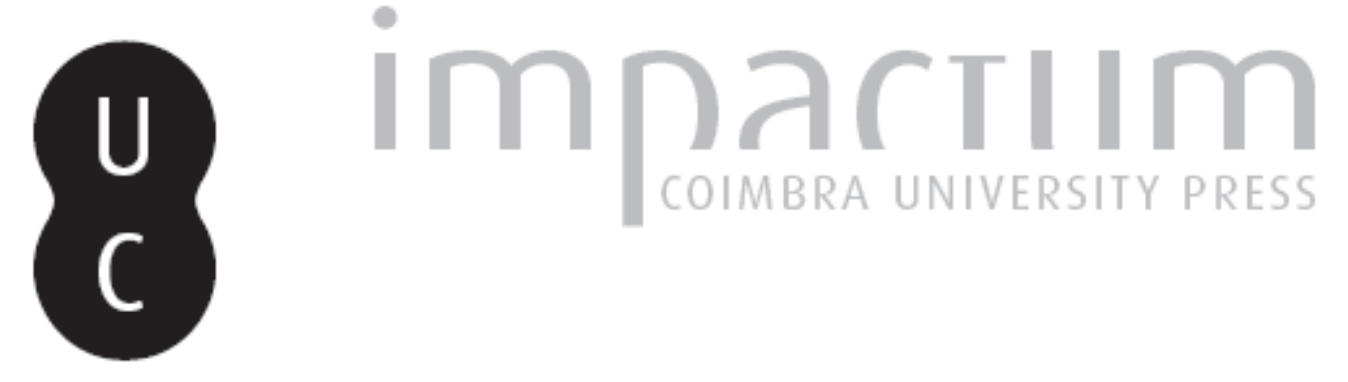

\title{
Vestígios para um amanhã
}

\section{Autor(es): Gomes, Sérgio Alexandre}

Publicado por: Imprensa da Universidade de Coimbra

URL persistente:

URI:http://hdl.handle.net/10316.2/43076

DOI:

DOI:http://dx.doi.org/10.14195/0870-4112_3-3_8

Accessed : $\quad$ 26-Apr-2023 11:32:43

A navegação consulta e descarregamento dos títulos inseridos nas Bibliotecas Digitais UC Digitalis, UC Pombalina e UC Impactum, pressupõem a aceitação plena e sem reservas dos Termos e Condições de Uso destas Bibliotecas Digitais, disponíveis em https://digitalis.uc.pt/pt-pt/termos.

Conforme exposto nos referidos Termos e Condições de Uso, o descarregamento de títulos de acesso restrito requer uma licença válida de autorização devendo o utilizador aceder ao(s) documento(s) a partir de um endereço de IP da instituição detentora da supramencionada licença.

Ao utilizador é apenas permitido o descarregamento para uso pessoal, pelo que o emprego do(s) título(s) descarregado(s) para outro fim, designadamente comercial, carece de autorização do respetivo autor ou editor da obra.

Na medida em que todas as obras da UC Digitalis se encontram protegidas pelo Código do Direito de Autor e Direitos Conexos e demais legislação aplicável, toda a cópia, parcial ou total, deste documento, nos casos em que é legalmente admitida, deverá conter ou fazer-se acompanhar por este aviso.

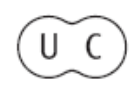




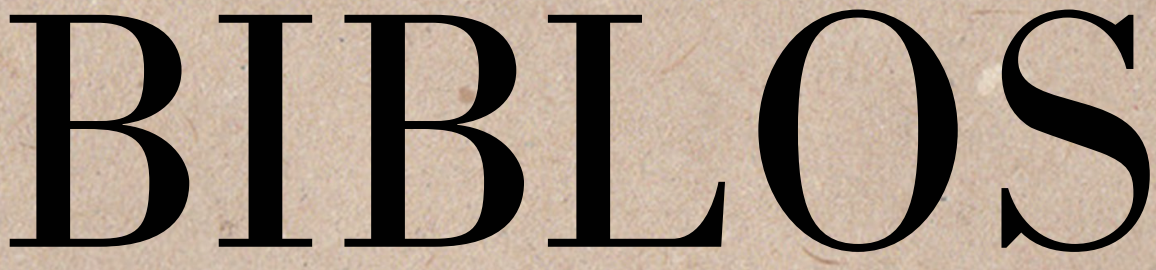

Revista da Faculdade de Letras da Universidade de Coimbra

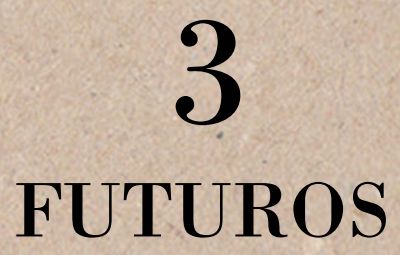

NÚMERO 3, 2017

3. ' SÉRIE 


\title{
VESTÍGIOS PARA UM AMANHÃ
}

\author{
Traces for a tomorrow \\ SÉRGIO ALEXANDRE GOMES \\ sergioalexandregomes@gmail.com \\ Centro de Estudos em Arqueologia, Artes e Ciências do Património. \\ Universidade de Coimbra
}

\author{
DOI \\ https://doi.org/10.14195/0870-4112_3-3_8 \\ Recebido em setembro de 2016 \\ Aprovado em novembro de 2016
}

Biblos. Número 3, 2017 • 3. a Série

pp. $169-192$ 


\title{
SÉRGIO ALEXANDRE GOMES
}

\section{RESUMO.}

Neste texto pretendemos contribuir para a discussão sobre como no estudo do passado se pode proporcionar uma oportunidade de trabalhar nas condiçōes do futuro. A partir das propostas da arqueologia simétrica, vamos enfatizar o modo como uma práxis guiada pelo princípio da simetria e uma atitude de compreensáo permitem o surgimento de pontos de vista que resistem aos imperativos disciplinares. Estes pontos de vista permitem produzir um registo arqueológico desalinhado da direçáo inicial de pesquisa. No seu desalinhamento, o registo arqueológico transforma-se num foco de resistência para reabrir as possibilidades da disciplina participar na configuraçáo das possibilidades do futuro.

Palavras-chave: Arqueologia simétrica; Compreensão; Registo arqueológico; Resistência; Por vir.

\begin{abstract}
.
In this paper we aim to contribute to the discussion on how the study of the past may afford opportunities to work upon the conditions of the future. Taking symmetrical archaeology as a reference point, I will argue that praxis, guided by the principle of symmetry, and an attitude of understanding, permits the emergence of points of view that resist disciplinary imperatives. These points of view create an archaeological record misaligned with the initial direction of research, and in this misalignment, the archaeological record becomes the focus of resistance to re-opening the possibilities of the discipline in the shaping of the future.
\end{abstract}

Key-words: Symmetric archaeology; Understanding; Archaeological record; Resistance; Becoming. 


\section{INTRODUÇÃO}

A História é a solicitação do futuro e não do passado. É proposta de sobrevivência por superaçấo das contingências, como reformulação da auto-identificação. É constante o efeito de cada impacto humano de "si para consigo" no confronto de "si" com o "outro", com o "tu" das coisas e das pessoas, "soi-même comme un autre” (Ricouer, 1990). É o renovado momento primordial do ser humano para continuar a ser. É a experiência primordial que se conta, narrando, como troca de experiências, que constitui o com-viver humano.

(Torres 2000: 23-24)

Na citação com que abrimos este texto, J. Veiga Torres define o campo a partir do qual pretendemos situar o papel do estudo do passado na delineação do porvir e na abertura das condiçóes do por vir. No desempenho desse papel, o estudo do passado é, fundamentalmente, um exercício de alteridade. É um exercício de alteridade na medida em que se faz num constante desajustamento das condiçôes que o presente dá a experimentar para viabilizar o estudo de um outro. Um desajustamento que abre a possibilidade de refazer o futuro enquanto projeto. Esta questão será desenvolvida com Michel de Certeau (1987 [1974]) a propósito do modo como concebe a operação historiográfica. Tal operação, enquanto desajustamento com as condições do presente, é feita num deslocamento das analíticas que desenvolvemos com a experiência dos testemunhos de que dispomos para o estudo do passado. Pelo deslocamento das analíticas, lança-se a possibilidade do alargamento das perspetivas sobre esse passado. Na discussão destas possibilidades de alargamento, analisaremos as propostas da arqueologia simétrica (e. g. Olsen et al. 2012) ${ }^{1}$, na qual a simetria é o eixo a partir do qual se pode potenciar os

A arqueologia simétrica é a designação de um grupo de trabalho no qual se encontram reunidos
vários investigadores, cujo ponto em comum reside no uso do princípio da simetria na condução
do trabalho arqueológico. Este princípio, como veremos mais à frente, apareceu no âmbito dos
Science and Technology Studies pela mão de David Bloor (1976), sendo desenvolvido por outros
autores, como Bruno Latour (1993), por exemplo. Na atualizaçáo do princípio por parte do grupo
de trabalho acima mencionado existe uma grande diversidade de perspetivas (e. g. Olsen 2003; 
deslocamentos necessários para pensar o passado diferentemente. Como veremos, tais propostas dáo ênfase a uma prática de compreensão na qual pode irromper a abertura ao por vir. $\mathrm{Na}$ análise desta prática, acompanha-nos o modo como Rui de Magalhães (1999; 2006) concebe a compreensão, fazendo-a um modo de atuação sobre a realidade em que nos encontramos imersos. Finalizaremos a discussão com o exemplo do trabalho de dois arqueólogos - Alfredo GonzálezRuibal (2006) e Joana Alves Ferreira (2013) - cujos deslocamentos contribuem para cartografar a possibilidade da arqueologia se transformar num modo de recriação do entrosamento entre o passado, o presente e o futuro e, nesse entrosamento, afirmar-se enquanto práxis que desafia o por vir.

\section{OS VESTÍGIOS ARQUEOLÓGICOS NA LINHA DOS LIMITES E POSSIBILIDADES DO PRESENTE}

[A] imagem do passado mantém o seu valor primeiro de representar aquilo que falta. Com um material que, está necessariamente aí, mas é conotativo

2010; 2007; 2012; Olsen et al. 2012; Shanks 2007; Webmoor 2007; 2012; Witmore 2007; 2013), atravessada pela necessidade de se contextualizar o trabalho dos arqueólogos na sua contingência histórica para se compreender o sentido do conhecimento que produzem. Tal preocupação retoma, assim, o trabalho teórico de diversos arqueólogos, como nos explica Michael Shanks (ib.). Para mais informação acerca das propostas da arqueologia simétrica, sugere-se a consulta, por exemplo: do volume 20 da Current Swedish Archaeology, no qual um texto de B. Olsen (2012) é comentado por um vasto conjunto de arqueólogos; do volume 18 da revista Complutum editado por Alfredo González-Ruibal (2007), no qual se encontram traduzidos os textos de Olsen (2007), Shanks (2007), Webmoor (2007) e Witmore (2007) e um conjunto de reaçóes de arqueólogos espanhóis às propostas da arqueologia simétrica; da síntese crítica, escrita em português, por Ana Vale (2015) sobre a relação entre a arqueologia e o pensamento pós-humanista que anima a arqueologia simétrica; e dos trabalhos de Gonçalo de Carvalho Amaro $(2013,2014)$, nos quais também é desenvolvida tal problematização. A consulta destes textos permite verificar que a arqueologia simétrica se encontra inserida numa reflexão mais ampla sobre "os objetos", na qual é denunciada a centralidade do "ser humano" no modo como as diferentes disciplinas desenvolvem os seus discursos. Neste sentido, é também de referir o livro Objetos Selvagens, editado por Godofredo Pereira (2012), no qual se encontra reunido um conjunto de contribuiçóes, escritas em português, de autores com diferentes formaçôes disciplinares, cuja leitura contribui para a compreensão da transversalidade das questōes que arqueologia simétrica coloca ao estudo dos vestígios materiais do passado. 
de um passado na medida em que, inicialmente, remete a uma ausência e introduz também a falta de um futuro. Um grupo, sabe-se, não pode exprimir o que tem diante de si - o que ainda falta - senão por uma redistribuição do seu passado. Também a história é sempre ambivalente: o lugar que atribui ao passado é, igualmente, uma maneira de dar lugar ao futuro (Certeau 1987 [1974]: 93)

No excerto acima apresentado, Michel de Certeau dirige-nos a atenção para um entrosamento entre o passado, o presente e o futuro no qual se criam as condiçóes para que se possa experimentar aquilo que falta. No processo de conotação que anima a presentificação do passado há um efeito contrário, no qual se constata o irredutível silêncio dos testemunhos do passado. Neste silêncio, os testemunhos, apesar de intrinsecamente conotativos, demarcam-se de todas as conotaçóes, abrindo-se enquanto focos de resistência ao sentido que lhes queremos conferir. Uma resistência onde o passado se afigura enquanto uma ausência. Os testemunhos do passado, enquanto focos de resistência às conotaçóes do presente, tornam-se objetos a partir dos quais se pode fazer uma cartografia do presente; uma cartografia das conotaçóes que conformam o presente e dos movimentos que tecemos na sua construção. Uma cartografia crítica na qual se abrem as possibilidades de dar lugar ao futuro; dar lugar a um modo de "simbolizar o limite e através disto tornar possivel uma ultrapassagem" (ib.) do horizonte de sentido em que nos encontramos. É neste desajustamento que o estudo do passado pode renovar o seu propósito, afirmando-se como prática de temporalização dirigida à produção de diferentes modos de compreender o presente e, assim, multiplicar as possibilidades de conhecer o passado e pensar o futuro.

O estudo do passado toma, então, a forma de uma prática de compreensão e de desafio às condiçóes do presente. A esta prática Michel de Certeau dá o nome de operação historiográfica (ib.: 65-66). A autoridade do conhecimento que se produz nesta prática gere-se entre os lugares, os procedimentos de análise e a escrita que dão forma a este conhecimento. É uma prática com uma dinâmica disciplinar cujas relaçóes de poder e saber se desenvolvem no sentido de: 
- definir os parâmetros de validade do conhecimento produzido;

- negociar a utilidade do conhecimento enquanto modo de regulação/ emancipação social;

- e, por último, de posicionar e julgar esse conhecimento, designadamente no que diz respeito à sua potência transformadora, face ao projeto da própria disciplina; um projeto feito entre agendas de distinta natureza que, no modo como se cruzam, conferem ao conhecimento uma dimensão "legendária ou polémica", colocando-o em linha com perspetivas "reacionárias ou revolucionárias" (ib.: 93).

No modo como se desenvolve a operação historiográfica é delineado o modo como o conhecimento do passado pode contribuir para a compreensão do presente e, por conseguinte, para abrir as condiçóes para se pensar o futuro. Neste sentido, na relação entre a política e a disciplina, o desafio da operaçáo historiográfica é o de se manter comprometida com o seu propósito inicial: o de tornar possível a desarticulação com as condições que a tornaram viável e imprimir ao seu rumo uma direçáo que possibilite um deslocamento face aos limites de tais condiçôes. Só assim, libertando-se do impulso inicial que faz da prática um encadeamento de açôes com uma finalidade inicialmente definida, se torna possível criar o distanciamento necessário para se cartografar as possibilidades do presente. Uma cartografia que se desenha ao lado do presente, ao lado das políticas do presente, com o propósito de ensaiar uma diferente simbolização dos seus limites.

Olhando para a história da arqueologia enquanto enredo de dinâmicas que partem de distintas operaçóes historiográficas, podemos ensaiar uma perspetiva que faz dessa história um confronto de distintas propostas de simbolização dos limites da disciplina, de diferentes horizontes de sentido que os vestígios arqueológicos dão a experimentar e, por conseguinte, de um alargamento da possibilidade de se compreender o presente e pensar o futuro. Analisando, por exemplo, o momento em que a arqueologia nasce entre as práticas dos antiquários, podemos ver que a congregaçáo num mesmo espaço - o Gabinete - de objetos de diferente natureza (dispostos de acordo com mesma ordem) viabilizava um exercício de comparação que, simultaneamente, reforçava a 
ordem da coleção e permitia a especificação da análise a desenvolver a partir de cada um dos conjuntos de objetos. Assim, essa ordem, tratando-se de uma grelha que afasta ou aproxima os objetos em função de determinados critérios, vai abrindo a possibilidade para que seja possível ver brechas na coleçáo, isto é, permite dar conta de descontinuidades que tanto anunciam aquilo que falta como interpelam a operacionalidade instituída pela ordem das coisas no lugar do estudo (Thomas 2004: 8-16; Schnapp 1997). Seria nessa interpelação à ordem das coleçôes que se constituiria uma nova ordem, na qual se encontram as condiçôes para viabilizar a arqueologia enquanto ciência, enquanto uma disciplina com uma analítica assente no cruzamento da ordem tipológica, tecnológica e estratigráfica ${ }^{2}$. Na interpelação da ordem pré-estabelecida, que desenhava os limites espaciais do Gabinete e a sua topografia social, começa a construir-se também a possibilidade de um novo espaço para a coleção dos objetos: o Museu. Uma possibilidade que se gera no diálogo entre as dinâmicas de uma disciplina em formação - a arqueologia - e a globalização do Estado-Nação enquanto unidade de referência de organização de comunidades e territórios (ib; Bennett 2004; Díaz-Andreu 2007; Gomes 2011: 135-164; Trigger 1992 [1989]). Um diálogo que se adensa com o propósito de converter o passado, a identidade e o património num conjunto de dispositivos ao serviço de uma biopolítica ${ }^{3}$ que conforma os meios pelos quais as comunidades se imaginam/

2 Entre o antiquarismo e a arqueologia processou-se, entâo, um alargamento dos limites do conhecimento que se podia ter daquilo que se encontrava congregado no espaço do Gabinete. Com efeito, a especificação da análise das coleçôes foi estreitando a sua relação com outras práticas que conformavam o Gabinete enquanto local de estudo e local de visita. Neste processo de especificação da análise, a preocupação com o enquadramento espacio-temporal dos objetos levou a uma especificação e aferição dos processos de recolha, nomeadamente através de escavaçôes arqueológicas, com os quais se foi forjando uma nova ordem para a coleçáo. Uma ordem assente na relação entre a tipologia, a tecnologia e a estratigrafia (Schnapp 1997: 303) que permitia a construçáo de esquemas evolutivos e difusionistas que participavam na configuraçấo das coleçôes. Uma ordem que, pela sua dinâmica de aferição, estabelece as fundaçôes da arqueologia enquanto disciplina científica, enquadrada numa epistemologia positivista ( $i b$; Diaz-Andreu 2007: 368-407).

3 A biopolítica é, seguindo o pensamento de Michel Foucault (1994 [1976]: 141-142), um tipo de poder que coloca em diálogo os sistemas de produçáo e de controlo centrados na disciplina do 
fabricam enquanto uma unidade entre unidades e, assim, se forjam enquanto projeto de futuro (e.g. Anderson 2005 [1983]; Guillaume 2003 [1983]).

Se continuássemos a acompanhar o desenvolvimento da arqueologia ao longo do século XX, continuaríamos a encontrar interfaces que testemunham um diálogo edificante entre a prática arqueológica e os desafios do seu contexto social e político. Um diálogo onde a arqueologia vai refazendo a utilidade do conhecimento que produz, a finalidade da sua prática e a sua capacidade de participar nas cristalizaçóes e transgressóes do presente. Porém, não é objetivo deste texto demorarmo-nos nesta genealogia e encontrarmos a especificidade e a atualidade de cada momento desta relação. Em contrapartida, analisaremos apenas o exemplo das propostas da arqueologia simétrica para o desenvolvimento da prática arqueológica, no sentido de aí encontrar um modo como a arqueologia pode participar num exercício de construção das condiçóes para abrir o pensamento ao futuro; ao por vir.

\section{A ARQUEOLOGIA SIMÉTRICA}

To assume the past is gone accords the things of archaeology the positions of intermediaries rather than full-blown mediators. We run afoul of the things when we assume a demarcated, disconnected past as the ontological starting point for what we do in the present. Archaeology does not discover

corpo, desenvolvidos a partir do século XVII em diferentes instituiçóes (a prisão, por exemplo), e os sistemas de vigilância e regulaçáo do corpo-espécie, que emergem nos meados do século XVIII no âmbito das políticas demográficas e de saúde pública. Trata-se de um governo que, tácita e taticamente, molda os comportamentos através de uma "tecnologia de face dupla anatómica e biológica, individualizante e especificante, virada para as possibilidades do corpo e contemplando os processos da vida" (ib.: 142), no sentido da fabricação dos indivíduos necessários aos projetos das unidades estato-nacionais. Neste contexto, o passado, o património e a identidade associam-se a este governo contribuindo com a edificação de dispositivos (o museu e o monumento, por exemplo). Nestes dispositivos, a disciplina anátomo-política encontra outros modos de individualização e especificação (através da formação de públicos-alvo, por exemplo). Simultaneamente, as normas que regulam o corpo-espécie, encontram sob o signo da identidade, um modo de naturalizar do ideal anatómico e ecológico que pretendem forjar. 
the past as it was; archaeologists work with what has become of what was; what was, as it is, always becoming.

(Olsen et al. 2012: 6)

O modo como o passado e os testemunhos materiais que usamos no seu estudo são perspetivados no âmbito da arqueologia simétrica é um dos pontos cruciais das suas propostas. Na citação com que iniciamos esta secção encontra-se enunciado um conjunto de ideias que definem o programa da arqueologia simétrica:

- o passado náo é entendido enquanto um tempo demarcado do presente, que funcionaria, no âmbito da prática arqueológica, enquanto ponto ontológico de referência para o desenvolvimento da produção do seu conhecimento;

- o passado, enquanto projeto do presente, funciona, como outros projetos do presente, enquanto um elemento por vir;

- deste modo, os testemunhos materiais com que trabalhamos em arqueologia náo são intermediários de um processo que nos levaria à descoberta do que aconteceu no passado, mas os mediadores que nos permitem participar no porvir do passado;

- a arqueologia trabalha com testemunhos em devir, sendo o seu trabalho um modo de cuidar das condiçóes desse devir.

Esta perspetiva sobre o passado e do papel da arqueologia no seu estudo tem alguns pontos em comum com a operação historiográfica de M. de Certeau (1987 [1974]) que abordámos anteriormente, designadamente enquanto um trabalho centrado nos limites da experiência de uma dada situaçáo, com o propósito de exceder as suas possibilidades de sentido. Ou seja, trata-se de um trabalho que interfere nas condiçóes de devir da experiência de uma determinada realidade e, por conseguinte, nos limites e possibilidades das condições do seu porvir. Nesta ordem de ideias, o propósito da arqueologia, náo sendo uma prática que se desenvolve em funçáo de um ponto de referência fixo, na medida em que o acesso a tal ponto não é possível, trabalha no sentido de transformar este seu limite na linha a partir da qual pode operar os deslocamentos necessários 
para encontrar outros pontos de aferição. Nestes deslocamentos, a arqueologia tem a oportunidade de se revisitar enquanto disciplina que:

- é um modo de alargar o pensamento sobre os testemunhos materiais; - é uma fonte de conhecimento resultante da experiência desses testemunhos, focado na análise das suas condiçôes de devir;

- e, por último, pode tomar a forma de um compromisso face a um conjunto de desafios do mundo contemporâneo.

Nesta dinâmica, a simetria é um princípio epistemológico e ético que vai no sentido de operacionalizar uma analítica que, assumindo-se enquanto parte integrante de uma agenda do presente, se esforça por resistir ao ímpeto dos seus preconceitos (Olsen et al. 2012: 12-14). Como refere Michael Shanks (2007), a ideia de uma "arqueologia simétrica" encontra-se ligada ao princípio da simetria sugerido pelo filósofo e sociólogo da ciência David Bloor (1976). Este princípio implica uma imparcialidade por parte do investigador da ciência no estudo da verdade ou falsidade, racionalidade ou irracionalidade, sucesso ou insucesso de um dado projeto de conhecimento, devendo o seu propósito ser o de compreender o modo como se processou a mediação entre uma natureza, que não fala por si, e o conhecimento dessa natureza. Desta análise resulta uma problematização do trabalho do cientista enquanto agente inserido numa teia de atores que se relacionam numa prática de mediação e tradução (Shanks 2007: 589-590). O princípio de simetria apela, deste modo, a uma atitude compreensiva que procura cartografar o modo como sujeitos, meios e objetos de análise interagem no sentido de edificar um determinado sentido para a sua experiência ${ }^{4}$. Tendo como referência este movimento da análise sugerido pelo

\footnotetext{
4 O princípio de simetria convida a uma fuga à construção de u ma história da ciência feita com base numa ideia de progresso, na qual se acumulam em oposiçấo os conhecimentos obsoletos e os conhecimentos eficazes. Nessa fuga, que é então proporcionada pela compreensão, é possível criar um afastamento da ideologia do progresso e da via única até constatarmos que, como nos adverte Boaventura Sousa Santos, "o determinismo mecanicista é o horizonte certo de uma forma de conhecimento que se pretende utilitário e funcional, reconhecido menos
} 
princípio de simetria, M. Shanks (ib.: 590) salienta que o estudo do passado não é tanto uma questáo de força da evidência (como se a dado momento fosse possível comprovar de modo inequívoco qualquer conotaçáo que exceda a presença dos testemunhos do passado), mas uma questáo de compreender o modo como os arqueólogos trabalham com mediadores de natureza distinta (objetos, representações, pessoas, entidades orgânicas e inorgânicas...) a partir dos quais se constitui o processo arqueológico. Não sendo uma questão de força de evidência, a simetria traz à arqueologia a proficuidade da força de trabalhar nos limites e nas possibilidades de conhecer os testemunhos para além das relaçóes de dualidade entre o passado e o presente, os agentes e as estruturas, as pessoas e os artefactos, as formas biológicas e os valores culturais (ib.).

A simetria, enquanto princípio operacionalizador, desenvolve-se na valorizaçâo de quatro componentes da prática arqueológica: processo, criatividade, mediação e distribuição (ib.: 591). O processo é entendido na sua iteratividade, abertura e incompletude, características que fazem com que arqueólogos e passado se constituam mutualmente nesta prática. Na sua abertura, o processo permite que a arqueologia receba contribuiçóes alheias à disciplina, funcionando como elemento de congregaçáo de múltiplas perspetivas e trabalhos sobre o passado (ib.). Enquanto processo aberto, a arqueologia faz-se na renovação dos meios de ativação entre os arqueólogos, os seus meios de análise e os testemunhos do passado, ou seja, é um processo criativo. Tal criatividade é possível porque o passado, enquanto elemento por vir, não é representado como algo que acabou

pela capacidade de compreender profundamente o real do que pela capacidade de o dominar e transformar" (2001: 17). O horizonte do determinismo mecanicista rege-se, deste modo, por um esquema assimétrico que, da experiência do mundo, apenas valoriza aquilo que pode controlar e maximizar. Nessa dinâmica, a eficácia deste horizonte de sentido é reificada pela capacidade da racionalidade cognitivo-instrumental instaurar um regime de verdade, no qual as outras formas de racionalidade são desautorizadas e reenviadas para outras formas de saber excluídas pelas ciência. Face a este ímpeto de dominação e transformação, provocador de incompreensíveis atos de destruição, é necessário guiarmo-nos por um "paradigma de conhecimento prudente para uma vida decente" (ib.: 37), cujo horizonte se constitui entre a possibilidade de saber explorar a simetria entre o conhecimento científico-natural e o conhecimento científico-social, entre o local e o total, entre conhecimento científico e o senso comum, entre o conhecimento e o autoconhecimento e, por último, entre o desconhecimento e o auto-desconhecimento. 
algures numa linha de tempo, mas enquanto produto de um diálogo genealógico entre as condições do presente e do futuro (ib.: 591-592). Neste sentido, o trabalho dos arqueólogos é um trabalho de mediação e tradução no qual se ensaiam métodos de análise e poéticas que, para além de responderem a solicitaçôes de carácter disciplinar, são meios de responder a um princípio de responsabilidade e justiça de falar por algo ausente (ib.: 592). Por último, enquanto processo de criação e mediação, a arqueologia é uma arte de distribuição, na medida em que se desenvolve num constante trabalho de (re)contextualização, ou (re)mediação, dos testemunhos materiais (ib.: 592-593). Ou seja, trata-se de um trabalho de (re) criação de (des)articulaçóes que excedem as relaçôes de dualidade que possibilitaram a emergência da arqueologia no quadro da modernidade (ib.: 593-594).

A natureza do trabalho de distribuição, inerente à prática arqueológica, faz com que a arqueologia seja, náo apenas o resultado do trabalho dos arqueólogos, mas aquilo que se constitui a partir desses resultados, na medida em que se produz uma realidade plena de meios de ativaçáo por parte de outros intervenientes sociais (Olsen et al. 2012: 56-57). Tal abertura duplica a necessidade de uma relaçáo de responsabilidade e compreensão dos arqueólogos para com o seu trabalho e incita à criação de novos eixos de simetria a partir dos quais se possa explorar a iteratividade, abertura e incompletude do processo arqueológico. Uma simetria que, colocando lado a lado tudo aquilo que compóe a nossa ecologia de trabalho, incita a um permanente exercício de compreensão dos limites e possibilidades da disciplina e da justiça que se pode fazer face aos testemunhos materiais do passado 5 . Talvez por isso, o projeto da arqueologia simétrica, enquanto disciplina das coisas, seja encarado pelos seus proponentes da seguinte forma:

\footnotetext{
5 O exercício de exceder os limites e possibilidades potenciado no esquema de dualidades criado na modernidade é um modo de resistir à biopolítica que se constitui a partir dessas oposiçóes. A anátomo-política do corpo humano (Foucault) é parte integrante duma economia do homem-máquina-artefacto cartesiana (Marques 1980: 257) que naturaliza o horizonte mecanista (Santos 2001) no qual se processa a produção disciplinar do conhecimento (ver notas de rodapé 2 e 3). Um processo animado pela capacidade de dominar e transformar o real, cujo ímpeto pode ser refreado pelo princípio da simetria e da sua valorizaçáo da compreensão enquanto modo de conhecimento e atuação no mundo.
} 
Our task therefore has less to do with transforming archaeology and more to do with understanding it. And, in so doing, we aim to generate other kind of narratives, more symmetrical accounts of archaeology and its common concern, things.

(Olsen et al. 2012: 11)

\section{SIMETRIA, COMPREENSĀO E INFINITO}

Without over-simplifying the world with an impoverished vocabulary of contradictory bifurcations, symmetry implies a profitable suite of perspectives and practices for recognizing the impact of things, ordinarily denied a stake in the modernist myths of the world. A symmetrical archaeology understands how human beings live with (to be distinguished from in) the world in terms of mixtures and entanglements. Such an understanding opens up new realms of possibility and new potentials for invention, which free us from the conceptual burdens associated with such a modernist predicament. This new ecology is full of possibilities for understanding what it is to be human; how the pasts are entangled in the present, how they have intimacy and relevance beyond being understood as obsolete or outmoded heritage.

(Witmore 2007: 559)

A compreensão não pode ser um acto subjetivo, mas um acontecimento. Nesse sentido, acrescenta algo ao mundo.

(Magalhães 1999: 138)

O primeiro excerto desta secção, de um dos textos sobre a arqueologia simétrica da autoria de Christopher Witmore, dá-nos conta da compreensão e da simetria numa dupla asserção: representação e atuação. A representação da constituição do mundo como uma profícua rede de predicados que, na sua associação, configuram vontades e ecologias de vontades em transformação. 
Transformaçóes que se operam numa aleatória dialética entre a potência de entidades orgânicas e inorgânicas que, continuamente, reificam as condiçóes de se ser humano, coisa, animal... ou outra qualquer entidade que o poder/saber nos permita fixar enquanto unidade com o mundo. $\mathrm{O}$ poder/saber arqueológico especificou-se enquanto analítica de testemunhos materiais e, na perspetiva simétrica, tem como objetivo criar, nesses testemunhos, as cisões necessárias para compreender a sua emergência e resistência na cadeia de ecologias que possibilitam/condicionam a sua existência com o mundo. A criaçáo dessas cisóes trata-se de um processo de delimitação de novos domínios de análise, de invençáo de novos modos de revelação do passado e, por conseguinte, de novas epistemologias. Nesse sentido, sendo um estudo sobre as origens é, em si mesmo, uma oportunidade de originar novos pontos de vista e novos modos de diálogo. Trata-se, deste modo, de um estudo e um exercício de temporalizaçáo da qual resultam novas entidades, ou novos objetos de análise, cujo estudo implica novas ordens e novas ligaçôes. Neste sentido, a simetria e a compreensão náo sâo apenas práticas de uma cartografia que tenta delimitar os meios pelos quais se constitui o mundo. A simetria e a compreensão, sendo estratégias de representação e apreensão, são também modos de atuação que, procurando não desperdiçar as possibilidades de uma experiência, desafiam a uma relaçáo profícua com o que não estava previsto no projeto de pesquisa. Nesta relação, existe uma procura focada na delimitação de novas entidades que, na sua novidade, podem transformar o rumo da pesquisa.

A arqueologia simétrica não tem como ponto de referência a possibilidade de acesso pleno a um momento no passado. Um acesso pleno que defina o ponto de aferição da verdade do seu conhecimento e, por conseguinte, sirva para edificar uma epistemologia única. Partindo desta impossibilidade, a epistemologia da arqueologia simétrica parece encontrar-se ancorada num pensamento ético, designadamente na sua relação com o desafio da justiça, colocando-se o repto de testemunhar por aquilo que nada nos diz de sua justiça, a náo ser apresentar-se no seu silêncio. Nessa procura de desenvolver uma analítica justa, a arqueologia torna-se uma prática de refazer os modos pelos quais nos podemos encontrar com os testemunhos do passado, demonstrando que, face ao seu silêncio, o desafio é aceitar o carácter incompleto do encontro e inventar novos modos de possibilitar 
um encontro sempre incompleto; sempre em falta. Assim, cabe aos arqueólogos, de modo irremediável, a paciência e a insistência em cuidar das possibilidades desse encontro. Um cuidado para com as coisas que implica a sua desarticulação de cenários em que se processa a sua domesticação; um cuidado que leva a pensar com as coisas (Webmoor 2012). Um cuidado que permite ampliar os modos pelos quais os arqueólogos constituem os seus interesses, a cientificidade da sua prática e a política do seu trabalho (Olsen et al. 2012: 204-207).

Neste trabalho de procura, paciência e insistência, a simetria e a compreensão, enquanto atitudes criativas, acrescentam novas ecologias ao mundo. Ou, na senda do que nos diz Rui de Magalhães no segundo excerto que abre esta secção, são atitudes que abrem as possibilidades de acontecimento ${ }^{6}$. Abrem a possibilidade de acrescentar algo ao mundo, participando na criaçáo de predicados, nas redes que entre si se formam, nos seus efeitos, na emergência de vontades, na configuração de novas, precárias e expectantes ecologias em transformação e no cuidado com a singularidade de um silêncio que resiste a tudo isto, fazendo dos testemunhos materiais do passado os mediadores que:

work to presence the past and hold memories not only of their human entanglement, not only of their contact with other non-human peers, but

6 Rui de Magalhães (1999) salienta que a compreensão não é apenas da ordem da receção, como de se de "um correlato da concepção do discurso como representação" (ib.: 155), mas da ordem da dádiva, na medida em que o seu trabalho de representaçáo é dirigido ao desajustamento que tem a vontade de anular as cristalizaçóes identitárias (ib.: 139), no sentido de possibilitar um encontro para além da benevolência da interpretação ou da conquista identitária (ib.: 125-126). Tal encontro, quando pensado na sua relaçăo com a palavra, faz da compreensão um "dar corpo à palavra, situando-se, por conseguinte, não sobre a palavra, náo depois dela, mas ligando-se directamente ao ponto em que a palavra se liga a si mesma. Deixar que ela use o sujeito que a atende, como lugar de refúgio, de júbilo e de auto-reflexão" (ib.: 139). É um encontro, nấo com o sentido, mas com as condiçôes de possibilidade sentido e, como tal, com a possibilidade de criar para além da causalidade que conforma o sentido. "A ligação compreensão/palavra não é nenhuma espécie de jogo (nem sequer de um jogo de morte): é a pura manifestação do em face de que fala Levinas" (ib.: 140). Neste em face, ontologia e ética tocam-se pela vontade de se ser justo e verdadeiro. "Ser justo, verdadeira e autenticamente, é muito diferente de actuar de acordo com a justiça. Ser justo só na compreensão se torna viável” (ib.: 140-141). A compreensão é um modo de se ser justo para com o porvir do mundo e para com a verdade por vir. 
also of themselves and their own irreducible, individual being.

(Olsen; Witmore 2015: 194)

No reconhecimento desta singularidade o trabalho arqueológico encontra a sua in-completude. Por um lado, reconhece nos testemunhos a resistência a uma ordem em que se revela a sua singularidade, por outro lado, essa singularidade apresenta-se como algo de irredutível a toda a prática de mediação e tradução, constituindo como uma zona de (des)conhecimento. Uma in-completude e um des(conhecimento) que potenciam a possibilidade de se refazer as ordens criadas para os testemunhos do passado, de ensaiar outros modos de compreensão que permitam pensar de modo diferente e de relacionamento com aquilo que de irredutível persiste. Nesta prática de se pensar diferentemente, a in-completude faz da arqueologia um trabalho centrado na singularidade das coisas com o mundo, no fascínio da irreduzível trama em que as coisas emergem e potenciam outras tramas.

A arqueologia trata-se, entâo, de um trabalho no qual o cuidado para com a finitude e a singularidade das coisas é a descoberta de uma resistência ao sentido e, simultaneamente, a uma resistência que, entre os eixos da simetria, remete para uma ausência que nos leva a compreender que:

É essa ausência, essa falta plena, que nos encosta ao nosso próprio limite. Porque essa falta - que "colocamos" no "objeto" - é essencialmente nossa. Uma falta que não é de nada. Que nada pode preencher porque é ela que nos constitui. Por isso, o fascínio é mais do que o desejo. Há entre ambos uma deslocação inordenável, um "espaço" impreenchível.

(Magalhães 2006: 13-14)

\footnotetext{
Uma zona de (des)conhecimento que é uma zona de auto(des)conhecimento. A este propósito, Boaventura Sousa Santos (2001: 58) escreve que "A condição epistemológica da ciência repercute-se na condiçấo existencial dos cientistas. Afinal, se todo o conhecimento é autoconhecimento, também todo o desconhecimento é autodesconhecimento". Trata-se, deste modo, de uma zona onde cada arqueólogo se pode encontrar face aos seus limites e possibilidades de continuar a fazer arqueologia, renovando o seu compromisso face ao silêncio dos testemunhos.
} 
A este espaço impreenchível, Rui de Magalhães dá o nome de infinito; uma terra de ninguém, habitada por forças aleatórias que se cruzam sem configurar um campo que permita uma conquista a partir da linha do limite (ib.: 13-16). É um espaço de suspeita e inconstituição (ib.). É um espaço de inconstituição porque com a terra de ninguém não há mediação possível, apenas o exercício das faculdades de compreender; de se ser outro e outro até se ser ninguém. É um espaço de suspeita forjado entre o desejo de uma verdade plena e o fascínio do indelimitável, no qual pode irromper a possibilidade

de uma outra forma de mediação. É, deste modo, um espaço de cisão entre domínios estratificados por relações de saber e poder e domínios sem qualquer tipo de diagrama. Entre eles, na linha do limite, joga-se a possibilidade de arrancar o futuro à derivaçáo das causas e à errância do aleatório e, aí, lançar as condiçôes para a constituição de uma nova perspetiva, que se julga mais justa e verdadeira face à resistência, singularidade e irredutibilidade dos testemunhos. Assim, apesar dos perigos deste infinito e de se tratar de uma terra inconquistável, parece ser o lugar no qual podemos expandir a relação com o porvir e recriar as condiçóes do por vir.

\section{REGISTOS PARA UM AMANHÁ}

O registo arqueológico é o suporte de inscrição da prática de tradução e mediação nas quais a arqueologia se constitui. Porém, o registo não se trata de uma objetivaçáo de um projeto anteriormente definido, sendo um elemento que participa na reorientação desse projeto. $\mathrm{O}$ registo, numa perspetiva simétrica, não é apenas um ponto de aferição do processo arqueológico, mas o ponto a partir do qual é possível uma reflexão acerca da experiência com as coisas e do registo desse encontro. Neste sentido, o registo é um processo de materialização (e. g. Lucas 2012) no qual se articulam a apreensão dos limites de uma dada situação, a vontade de se desarticular dessa situaçáo, a compreensão dos movimentos necessários ao deslocamento face a esses limites e a emergência de um novo elemento (um registo/acontecimento) em que se relançam as condiçóes do encontro com as coisas na expectativa de alargar as possibilidades do que pode acontecer. 
A questão acima aflorada parece estar no âmago do modo como Alfredo González-Ruibal (2006) reconduz os seus trabalhos de etnoarqueologia com comunidades não modernas de Espanha, Etiópia e Brasil. No seu trabalho, na sua interaçáo com estas comunidades, o arqueólogo refez o propósito da sua pesquisa, transformando a etnoarqueologia numa arqueologia do presente no sentido de explorar as múltiplas dimensóes da experiência. O registo deixou de ser o resultado de uma observação dirigida à produçáo de modelos que possibilitariam o desenvolvimento de uma análise analógica entre vestígios arqueológicos e registos etnográficos, para se transformar num registo de comunidades que, vivendo à margem de uma racionalidade moderna, se encontram em vias de desaparecer. A arqueologia do presente transforma, deste modo, as condiçôes de uma arqueologia que um dia possa vir a ser feita a partir do que restará destas comunidades, no sentido em que acrescenta testemunhos que, de outro modo, não existiriam para os arqueólogos do futuro. Este deslocamento do propósito inicial da pesquisa permite criar a abertura para registar a vida destas comunidades na sua confusão de tempos ${ }^{8}$, pessoas e objetos, sendo esta con-fusão que serve de analogia para o estudo dos vestígios das comunidades do passado?. Simultaneamente, a experiência com estas comunidades serve para que González-Ruibal refaça o sentido do conhecimento da sua prática enquanto

8 Esta con-fusão de tempos é discutida no âmbito da arqueologia simétrica a propósito da crítica à crono-política que conforma o pensamento moderno em que nasceu a arqueologia enquanto ciência. Como forma de combater as assimetrias que a partir daí se criam, dão ênfase a uma dimensão percolativa do tempo, que lhes parece mais adequada ao modo como se faz a experiência da temporalidade das coisas (Olsen et al. 2012: 136-156; Witmore 2013).

9 A este respeito, A. González-Ruibal (2006: 121-122) conclui da seguinte forma: "In my study of abandoned peasant houses in Galicia (Spain) (González-Ruibal 2005), I came to realize that messiness was key to grasp the gist of the overall phenomenon: mass emigration and traumatic cultural change. Decay was not the archaeological process that had to be cleared up to reach meaning about hidden social issues, but decay, dirt, disorder - the abject - were themselves the issues. It was not possible to understand rural Galicians without the ruinous and derelict landscape that mediated their lives. That could be, in my opinion, another substantial contribution of an archaeology of the present to a symmetrical archaeology. It offers another way of approaching the deep relations between humans and things that does justice to their essentially chaotic, messy nature. It should respect the collectives we study without asymmetrically sorting out and tearing apart its human and material components. It rethinks 
arqueólogo. Ao concluir o texto, o arqueólogo inscreve o seu registo enquanto análise/denúncia do modo como o confronto de racionalidades distintas - a racionalidade moderna e a racionalidade de comunidades rurais - se concretiza no desaparecimento de uma delas. Face aos espaços de abandono produzidos neste confronto, coloca-se o desafio de os entender enquanto feridas que é preciso mostrar e de que é necessário cuidar (ib.: 122). O registo arqueológico converte-se, então, num suporte de entrosamento entre o passado, o presente e o futuro que potencia as dimensóes do conhecimento arqueológico. Um entrosamento que faz desse registo um assunto político que visa interferir nas condiçóes de ação no presente e nas condiçóes de uma memória por vir.

Também acerca das possibilidades da relação entre os arqueólogos e o registo que produzem, Joana Alves Ferreira (2013) desenvolveu um projeto no sentido de documentar o trabalho de escavação do recinto pré-histórico de Castanheiro do Vento (Horta do Douro, V.N. de Foz Côa) ${ }^{10}$. Os mediadores do seu trabalho de documentação são 20 Polaroids, a partir das quais se propóe a ensaiar uma compreensão da campanha de escavação. Entre as possibilidades deste exercício, vai fazendo uma comparação entre a sua prática de registo e as práticas de registo em arqueologia, salientando os modos como cada uma delas cria uma diferente inteligibilidade para a mesma realidade. Assim, a um trabalho onde a fotografia é usada enquanto suporte de um registo sistemático e disciplinarmente aferido, opóe um registo que se assume enquanto um olhar em errância concretizado num conjunto de "imagens fragmentadas, testemunhos dos buracos de sentido de determinados discursos de uma verdade institucional" (ib.: 14). Deste modo, o trabalho de J. Alves Ferreira assume-se enquanto verdade paralela

anew the role of things (as "objects" are the outcome of such relations) in the construction of collectives (Latour 1993: 55)”.

${ }^{10}$ Este recinto murado, datado do III / 1.a metade do II milénios a.C., tem vindo a ser estudado no sentido de problematizar o seu papel enquanto dispositivo arquitetónico entrelaçado em práticas identitárias e territorialização da região do Alto Douro. Sobre a estação do Castanheiro do Vento, veja-se, por exemplo, Cardoso (2007) Vale (2011); e sobre as problemáticas deste tipo de arquiteturas pré-históricas, consulte-se Jorge (2005). 
à verdade institucional e disciplinarmente produzida pela equipa de arqueólogos. Não se trata de uma oposição direta ao trabalho dos arqueólogos, mas de um desajustamento face à ordem desse trabalho. Nesta oposição, as 20 Polaroids, enquanto elemento do registo arqueológico, emergem como focos de resistência à ordem da narrativa da campanha arqueológica. A sua condição de registo de um olhar errante não decreta qualquer sequencialização, pelo contrário, enfatiza a sua natureza fragmentária e aberta a (des) articulações. Face a isto, o documentário apenas se torna possível numa narrativa em forma de montagem que explora, sem cessar, as (des)conexóes entre os fragmentos. Com este arquipélago de "buracos de sentido", J. Alves Ferreira tem a expectativa de produzir um documentário inacabado aberto à "possibilidade de um trabalho de memória inventivo que irrompe contra a massiva história oficial” (ib.: 16).

Na compreensão que A. González-Ruibal e J. Alves Ferreira fazem da sua prática enquanto arqueólogos, há um alargamento das possibilidades do registo, convertendo-o num elemento que, pela resistência a um ímpeto inicial da pesquisa, participa ativamente na recriação dessa mesma prática. No trabalho de A. González-Ruibal, a superaçáo da assimetria entre o passado e presente, que o levaria a desperdiçar as possibilidades da sua experiência com as comunidades tradicionais, transforma-se na denúncia de um confronto entre racionalidades. A pesquisa assume uma dimensáo política que testemunha pelo que resiste à hegemonia da modernidade, demonstrando como a compreensão dos preconceitos inerentes à representaçáo do tempo potenciam uma problematizaçáo mais abrangente acerca da temporalidade das comunidades do passado. A analogia, em vez de procurar contextos descontaminados de presente, passa a dar conta de uma temporalidade onde, de modo profuso, se misturam elementos cronologicamente separados. Com J. Alves Ferreira, a questão desenvolve-se a partir da assimetria entre o sentido e o não sentido. $\mathrm{Na}$ documentação disciplinar do processo de escavação, o registo é um encadeado justificativo dos sentidos criados pelos arqueólogos. Em tal encadeado, encontram-se silenciados os impasses, os aleatórios e as suspensōes do sentido desse mesmo trabalho. Assim, desenvolvendo um diálogo entre a epistemologia e a estética, contrapóe a esse modelo um conjunto de registos errantes que, na sua (des)articulação, proporcionam uma edificação de sentido que resiste à dinâmica normativa da disciplina. 


\section{NOTA FINAL}

No trabalho dos dois arqueólogos, que apresentámos na secção anterior, há uma preocupação de fazer do registo um modo de multiplicar ativamente os olhares que o futuro possa vir a ter sobre a realidade da qual emerge. Sáo trabalhos que investigam as condiçóes em que os testemunhos emergem continuamente entre diferentes tempos. É uma investigação que vive da arte da mediação, da procura de um sentido, ou um leque de sentidos, entre o inquérito e os testemunhos. Ao atuar deste modo, os arqueólogos interferem com os propósitos iniciais da sua prática, alargando a sua ação a campos que, inicialmente, se encontravam excluídos. Nestes dois exemplos, o registo arqueológico é um modo de criação de vestígios para um amanhã; um amanhã qualquer. São registos que resistem à direção imposta pela situação inicial de onde partiram, na qual o amanhã se media enquanto previsão de um conjunto de resultados. São registos que, mais do que centrados nos outputs da pesquisa, se querem enquanto testemunhos da singularidade da experiência. São registos de uma relação de "si para consigo" no confronto de "si" com o "outro" (Torres 2000: 23). São registos de um "outro" e de um "si" que não estavam previstos na planificação da pesquisa, cuja emergência desafia a compreensão do presente e abre as possibilidades de um diálogo entre tempos. São registos que dão a ver aquilo que uma arqueologia assimétrica desperdiça; que produzem testemunhos que enunciam para além do previsto. São vestígios ancorados no presente que, enquanto focos de resistência à direção dos projetos desse presente, abrem as possibilidades de se fazer a memória da sua experiência. Neste alargamento da memória do presente joga-se com a potência do seu porvir e trabalha-se no sentido de um tempo por vir.

\section{AGRADECIMENTOS}

A Susana Soares Lopes, Ana Vale, Andreia Arezes, Joana Alves Ferreira e Andrew May pelas sugestôes que me foram fazendo durante a realização deste trabalho. A um revisor(a) anónimo(a), cuja leitura e sugestóes críticas contribuíram para o enriquecimento do texto. A investigação foi apoiada pela Fundação para a Ciência e a Tecnologia com a bolsa de pós-doutoramento SFRH/BPD/100203/2014 financiada por fundos nacionais do MCTES, POCH e FCE. 


\section{SÉRGIO ALEXANDRE GOMES}

\section{BIBLIOGRAFIA}

Amaro, Gonçalo de Carvalho (2013). "Da Matéria à Materialidade.Breves reflexôes sobre a relação

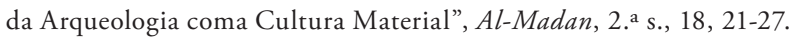

Amaro, Gonçalo de Carvalho (2014). "La arqueologia en sí misma. Una visión (a)simétrica de dos propuestas de Olsen", MATS. Materialidades. Perspectivas actuales em cultura material, 2, 2-22.

Anderson, Benedict (2005 [1983]. Comunidades imaginadas. Sobre a origem e a expansão do nacionalismo. Lisboa: Edições 70.

Bennett, Tony (2004). Pasts beyond Memory. Evolution, Museums, Colonialism. London/New York: Routledge.

Bloor, David (1976). Knowledge and Social Imagery. London: Routledge.

Cardoso, Joăo Muralha (2007). Castanheiro do Vento (Horta do Douro, Vila Nova de Foz Côa - Um Recinto Monumental do III e II milénio a.C.: Problemática do Sítio e das suas Estruturas à Escala Regional. Dissertaçáo de Doutoramento em Arqueologia apresentada à Faculdade de Letras da Universidade do Porto.

Certeau, Michel de (1987). A escrita da história. Trad. Maria de Lourdes Menezes. Revisấo técnica Arno Vogel. Rio de Janeiro: Editora Forense-Universitária [1974].

Díaz-Andreu, Margarita (2007). A World History of Ninetheen-Century. Archaeology. Nationalism, Colonialism and the Past. Oxford: Oxford University Press.

Ferreira, Joana Alves (2013). "Instantes da espera. A Polaroide enquanto experiência de expectativa", Almadan online, II s., 8, 1, 11-17. https://issuu.com/almadan/docs/al-madanonline (consultado a 30/7/2016).

Gomes, Sérgio Alexandre da Rocha (2011). O passado, a identidade e as teias do governo. Estudos sobre os entrelaçamentos das práticas de produção do conhecimento arqueológico e de construção da identidade nacional salazarista. Dissertaçáo de Doutoramento em Arqueologia apresentada à Faculdade de Letras da Universidade do Porto.

González-Ruibal, Alfredo (2005). "The need for a decaying past. An archaeology of oblivion in contemporary Galicia (NW Spain)”, Home Cultures, 2, 129-152.

González-Ruibal, Alfredo (2006). "The Past is Tomorrow. Towards an archaeology of the vanishing present”, Norwegian Archaeological Review, 39, 2, 110-125.

González-Ruibal, Alfredo (ed. 2007). "Arqueologia Simétrica: Un giro teórico sin revolución paradigmática”, Complutum, 18, 283-319.

Guillaume, Marc (2003). A política do património. Porto: Campo das Letras [1983]. 
Jorge, Susana Oliveira (2005). O Passado é redondo. Dialogando com os sentidos dos primeiros recintos monumentais. Porto: Ediçóes Afrontamento.

Latour, Bruno (1993). We have never been Modern. Cambridge, MA: Harvard University Press. Lucas, Gavin (2012). Understanding the Archaeological Record. New York: Cambridge.

Magalhães, Rui (1999). Paixōes e singularidades. Aveiro/Braga: Angelus Novus.

Magalhães, Rui (2006). Infinito singular. Sobre o não-literário. Leiria: Textiverso.

Marques, António (1980). "Normalização, poder e saber: a genealogia dos nossos dias", Revista da FCSH, 1, 245-258.

Olsen, Bjørnar (2003). "Material culture after text: re-membering things", Norwegian Archaeological Review, 36, 2, 87-104.

Olsen, Bjørnar (2007). "Keeping things at arm's length: a genealogy of asymmetry", World Archaeology, 39, 4, 579-588.

Olsen, Bjørnar (2010). In defense of Things. Archaeology and the Ontology of Objects. Plymouth: Altamira Press.

Olsen, Bjørnar (2012). "After interpretation: remembering Archaeology", Current Swedish Archaeology, 20, 11-34.

Olsen, Bjørnar; Shanks, Michael; Webmoor, Timothy; Witmore, Christopher (2012). Archaeology. The Discipline of Things. Berkeley: University of Califorina Press.

Olsen, Bjørnar; Witmore, Christopher (2015). "Archaeology, symmetry, and the ontology of things: A response to critics”, Archaeological Dialogues, 22, 2, 187-197.

Pereira, Godofredo (ed.) (2012). Objetos selvagens. Guimarães: Guimarães 2012 - Capital Europeia da Cultura em parceria com Imprensa Nacional - Casa da Moeda.

Ricoeur, Paul (1990). Soi-Même comme un autre, Paris: Seuil.

Santos, Boaventura de Sousa (2001). Um discurso sobre as ciências. Porto: Ediçôes Afrontamento [1987].

Schnapp, Alain (1997). The Discovery of the Past. New York: Harry N. Abram, Incorporated.

Shanks, Michael (2007). "Symmetrical Archaeology", World Archaeology, 39, 4, 589-596.

Thomas, Julian (2004). Archaeology and Modernity. London/New York: Routledge.

Torres, José Veiga (2000). "Por uma história humana como projecto, em ordem oculta de possibilidades e opçōes”, Ler História, 38, 5-27.

Trigger, Bruce (1992). Historia del pensamiento arqueologico. Barcelona: Editorial Critica [1889]. Vale, Ana Margarida Aparício do (2011). Modalidades de produção de espaços no contexto de uma colina monumentalizada: o sitio pré-histórico de Castanheiro do Vento, em Vila Nova de Foz 


\section{SÉRGIO ALEXANDRE GOMES}

Côa. Dissertação de Doutoramento em Arqueologia. Faculdade de Letras da Universidade do Porto.

Vale, Ana (2015). "A arqueologia e as coisas. A disciplina e as correntes pós-humanistas", Almadan online, II s., 20, 1, 41-49. https://issuu.com/almadan/docs/al-madanonline (consultado a $30 / 7 / 2016)$.

Webmoor, Timothy (2007). “'One more turn after the social in Archaeological reasoning? taking things seriously”, World Archaeology, 39, 4, 563-578.

Webmoor, Timothy (2012). "Symmetry, STS, archaeology”, in Graves-Brown, P.; Harrison, R.;

Piccini, A. (eds.), The Oxford Handbook of the Archaeology of the Contemporary World. Oxford: Oxford University Press, 105-120.

Witmore, Christopher (2007). "Symmetrical Archaeology: excerpts of a manifesto", World Archaeology, 39, 4, 546-562.

Witmore, Christopher (2013). "Which archaeology? A question of chronopolitics", in GonzálezRuibal, A. (ed.), Reclaiming Archaeology. Beyond the Tropes of Modernity, London/New York: Routledge, 130-144. 